\title{
Dialect and Foreign Language Features in Greek-Cypriot Advertising: Investigating Factors Influencing Recipients' Attitudes
}

\author{
Andreas Papapavlou and Melanie Satraki \\ University of Cyprus \\ andreasp@ucy.ac.cy, satraki.melanie@ucy.ac.cy
}

\begin{abstract}
Although advertising aims at promoting goods, by incorporating phenomena like code-mixing, it becomes an interesting area for linguists to study. In this paper, we aimed at investigating Greek-Cypriots' view of the appearance of dialect and foreign features in local advertising. In doing so, an effort was made to test influence by the medium used to present the advertisement or the stereotype reflected. The results support studies that showed preference towards the standard variety (Papapavlou 1998). However, advertisers' insistence on associating different types of products with different codes (Pavlou 1992, 2004) does not bear support.
\end{abstract}

\section{Introduction}

Since the establishment of the Republic of Cyprus, the linguistic situation of the island has been linked to that of identity. Although official language policy recognises Standard Modern Greek (SMG) as the official language of the Greek-Cypriot community, people never stopped using the Greek Cypriot Dialect (GCD) in their everyday life (Papapavlou \& Pavlou 1998; Karyolemou 2001). GCD has borrowed heavily from many different languages - since its history has been interlinked with that of over thirty-two countries (Varella 2006). English, as the lingua franca, has influenced many languages worldwide and in Cyprus, this does not appear only in the form of loanwords, but, also, in code-switching and code-mixing.

Extended research has been conducted within the area of education (Papapavlou \& Pavlou 2004, 2007; Yiakoumetti et al. 2006), on the use of the dialect (Papapavlou \& Kouridou 2007) and English (Papapavlou 1994, 1997; Goutsos 2005). Among these studies there have been more focusing

\section{(cc) BY-NC-ND}


on the issue of language attitudes. Although the most frequent conclusion is that people are more in favour of the standard variety rather than the dialect (Papapavlou 1998), what has been recently observed is that negative feelings towards GCD are declining (Tsiplakou 2003; Themistocleous 2007; Papapavlou $\&$ Sophocleous 2009). On the other hand, although English obtains an important position in people's speech, the native codes are still not threatened since they will always be an inseparable part of the community's identity (McEnteeAtalianis \& Pouloukas 2001).

Given that language attitudes constitute the topic of the present paper, it needs to be noted that the present paper focuses mainly on advertising. The most triggering issue about the language of advertising is that while "with other genres we usually know where our loyalties lie; with ads we are just confused" (Cook 2006: 3). Going a step further, it becomes obvious that attitudes towards the language of advertising become an even more fascinating topic.

\section{Attitudes to Language}

Attitudes have raised much discussion as to what they are and how they can be measured. Baker (1992) described attitudes as "construct[s] used to explain the direction and persistence of human behavior" (p. 10). Going one step further, Baker refers to the questionable relationship between attitude and action. Attitudes have been claimed to include three components: cognitive, affective and readiness for action. The first one refers to the beliefs related to a linguistic variety, the second one concerns feelings about it and the third one is associated with plans for action. However, in some cases people supported the maintenance of a language, even if they do not hold favourable feelings towards it. But, studies showed that actions may not always work as an indicator of people's attitudes (Choi 2003).

Garrett, Coupland and Williams (2003) discussed the main distinction in approaching language attitudes: 'societal treatment', 'direct measures' and 'indirect measures'. The first one, which has been the least used, concerns observation of people's reaction to a linguistic variety within society. Direct measurement refers to direct elicitation of people's attitudes and it can be done through questionnaires - with open-ended questions, likert scale etc - or interviews by asking people about their opinion on a linguistic code. Finally, indirect approaches can be observations or deceptive measurement where the participants are not fully aware of the purpose of the study.

The most famous indirect approach is the matched-guise technique. It was initially used by Lambert, Hodgson, Gardner and Fillebaum (1960) and it "involves playing recordings of [the same speaker] reading aloud the same passage of prose but using different accents, dialects or languages [as guises]" (Trudgill 1992: 51). After listening to each recording, the judges are asked to evaluate the 
speaker based on a questionnaire which usually includes a semantic differential scale of opposite adjectives.

\section{Advertising and the Field of Linguistics}

Although at first sight advertising seems to be solely a component of the marketing process, nobody can doubt that advertising is a kind of communication. Advertising is not as straightforward as other genres and aims at promoting products or promoting identities (Martin 2006; Piller 2001). Advertising language differs from ordinary language and it is so powerful that it manages to enter people's everyday language use (Kelly-Holmes 2005).

At a purely linguistic level, features appearing in advertisements concern phonology, morphology, syntax, semantics and pragmatics and have been extensively studied by linguists (Bruthiaux 1996; Cook 2006; Dyer 1982; Harris et al. 2002, Tanaka 1994; Vestergaard \& Schrøder 1985; Wyer 2002). Nevertheless, linguistics goes even deeper in advertising since phenomena of bi- / multilingualism and bi- / multidialectism are observed. Although existing research on these issues is not as rich as on the ones mentioned above, researchers have already come up with some interesting conclusions.

\subsection{The Use of Foreign Languages in Advertising}

As Kelly-Holmes argues, the use of foreign languages in advertising is 'symbolic' since it is recognised as a way of "constructing identities for the product [...] rather than communicating facts" (2005: 65). A general conclusion of the studies drawn on multilingual advertising is that certain languages are associated with certain products cross-culturally. Hence, French attributes fashion and elegance, Spanish is used as a sign of freedom and adventure, German signifies "reliability, precision, and superior technology" and Italian is linked to "good food and a positive attitude toward life" (Piller 2003: 172-173).

As far as English is concerned, it is the most frequent language appearing in multilingual advertising and, although it may be associated with the cowboy spirit, youth culture and hip hop rebellion, "internationally, English has become a general symbol of modernity, progress, and globalization" (175). Nevertheless, the role of the lingua franca in multilingual advertisements may be different from that of any other language. Piller argues that even if the recipients do not speak the foreign language used in an advertisement, they will be able to activate the stereotypes about that culture and "transfer them to the product" (Piller 2001: 163). Besides, this unique role of English in advertising has been supported by research within different linguistic settings (Rash 1996; Chen 2006; Krishnasamy 2007; Hornikx et al. 2010; Planken et al. 2010). 


\subsection{The Use of Nonstandard Varieties in Advertising}

It is claimed that although at the beginning advertising adopted a formal register, gradually it has come to adopt the characteristics of everyday communication (Kelly-Holmes 2005). This change prompted advertisers to use indigenous varieties to "create a feeling of community and to associate this with a particular product" (109).

For instance, Mutonya (2008) argues that advertisers in Nairobi use nonstandard forms to appeal to a greater number of audiences and portray the contemporary identity of the community and address taboo topics. On the other hand, Atkinson and Kelly-Holmes find the standard Castilian to be used as a 'globalising' language and to show modernity, whereas nonstandard Catalan stands as a means of establishing either solidarity or "local and often 'traditional' associations" (2006: 255).

\section{Advertising in the Greek-Cypriot Community}

When the British took over the administration of Cyprus from the Turks in 1878, the colonizers permitted the publication of the first Cypriot newspaper CYPRUS which included the first commercial advertisements. At that time, these 'announcements' were written in puristic Greek ("katharevousa"). However, at the beginning of the $20^{\text {th }}$ century, the archaic forms started gradually being simplified and, by the 1960s, Demotic Greek became the language of literary texts. Nonetheless, during this linguistic transition, Cypriot dialect features have been observed in advertisements of as early as 1912, in order to create a satirical effect (Sophocleous 2004).

The satirical use of the dialect still exists nowadays. But, research on the language of media and advertising has been limited (Karyolemou 1994, Pavlou 1992, 2001, 2004). Pavlou (1992) aimed at investigating dialect use in radio commercials. Pavlou claims that GCD is - successfully - used not only to create humourous effects, but also, to promote traditional food, products competing similar imported ones and products associated with the maintenance of traditional values. The reason why the dialect is preferred rather than the standard in advertising such products lies in the belief that recipients need to identify the lifestyle they employ with the product, and validate it through the depiction of it in other domains of their life.

Moreover, Pavlou (2001) further investigates the appearance of foreign language elements and how language choice in advertising functions as a 'carrier' of a desired Cypriot identity. Based on the view that advertising serves as a powerful sociopolitical tool used to promote values and identities, Pavlou concluded that advertising promotes a kind of bourgeois society, since products 
reflecting such a lifestyle are advertised through the use of SMG and foreign language elements. By contrast, the dialect is used to address lower-class people and, thus, promoting a traditional way of life.

In summing up, from the above-mentioned research on the language used in the Cypriot advertising, one realises that further investigation is essential. While previous efforts have investigated the use of the local and foreign varieties in advertising, none of the studies focused on people's view of the appearance of GCD, SMG and English features. Specifically, the aim of the current study is to provide answers to the following questions:

a) Do Greek-Cypriots have positive attitudes towards the appearance of GCD, SMG and English in advertising?

b) Does the stereotypical nature of a product (e.g. traditional or foreign culture-specific value) affect Greek-Cypriots' attitudes?

c) Does the medium (oral or written) used for the advertisements influence Greek-Cypriots' attitudes?

\section{The Study}

\subsection{Participants}

A total of 38 adult Greek Cypriots (20 males and 18 females) participated in the main study. The participants were randomly selected from middle-class families, from both urban and rural areas of Cyprus.

\subsection{Design}

For the purpose of the study, a two-part questionnaire was designed. The questionnaire consisted of four closed questions. After providing some personal information, the participants were asked to answer questions based on selfmade advertisements designed by the experimenters along with the assistance of a professional Cypriot advertiser. The language of the advertisement was decided to be closer to what is considered 'correct Cypriot' (i.e. Tsiplakou et al. 2005), since a more basilectal level might have triggered negative feelings towards a variety not used anymore in contemporary Cyprus (Papapavlou \& Sophocleous 2009). For Part A, the participants were asked to study three categories of advertisements and then answer three questions. Further details about the advertisements are found in Table 1. 
Table 1.

Features of self-made advertisement (Part A)

\begin{tabular}{|c|c|c|c|c|c|c|c|c|}
\hline \multicolumn{4}{|c|}{ CATEGORY I STEAKHOUSE } & \multicolumn{3}{c|}{ CATEGORY II ZIVANA } & \multicolumn{2}{c|}{ CATEGORY III CLOTHING } \\
\hline & Ib & Ic & Ila & & Ilc & IIla & & IIIc \\
la & SMG with & SMG & SMG with & IIb & SMG & SMG & IIIb & SMG with \\
SMG & $\begin{array}{c}\text { English } \\
\text { feath GCD } \\
\text { fitures }\end{array}$ & $\begin{array}{c}\text { English } \\
\text { features }\end{array}$ & $\begin{array}{c}\text { SMG } \\
\text { features }\end{array}$ & $\begin{array}{c}\text { with GCD } \\
\text { features }\end{array}$ & $\begin{array}{c}\text { with GCD } \\
\text { features }\end{array}$ & SMG & $\begin{array}{c}\text { English } \\
\text { features }\end{array}$ \\
\hline
\end{tabular}

The selection of the above products was based on how these are usually perceived by the members of the community under study: the steakhouse signifies luxury and foreignness, zivana-a local drinking spirit-is associated with the local tradition, and casual clothing is normally considered as neutral since it is part of everyday life.

For the first two questions, participants were instructed to evaluate the three advertisements of each category by comparing them and ranking them $(1,2$, 3 from high to low) with the use of a table of several items (see Tables 3 and 4). Whereas in Question 1 they were asked to evaluate the advertising text in terms of aesthetics, vocabulary and target audience, for Question 2, they should evaluate the advertised product in terms of quality, price and target audience. The way of perception of the items is left to the judges (McGroarty 1996). These questions studied attitudes towards the three codes, while, at the same time, they would reveal any influence by the nature of the product. Then, Question 3 should be answered through categorization of the advertisements as whether they should be presented in oral media (radio, TV etc) or written media (magazine, newspaper, leaflet etc). This was an effort to find out whether people's views of the codes are affected by the mode of communication - oral or written.

Finally, Part B included a question asking participants to rank $(1,2,3$ from high to (ow) three advertising texts of each of the four products given. Although the format of the question differed from that of Question 1, the purpose was similar. Further details are found in Table 2.

Table 2.

Features of self-made advertisement (Part B)

\begin{tabular}{|c|c|c|c|c|c|c|c|c|c|c|c|}
\hline \multicolumn{3}{|c|}{ CYPRIOT TAVERN } & \multicolumn{3}{|c|}{ CHAMPAGNE } & \multicolumn{3}{|c|}{ FORMAL CLOTHING } & \multicolumn{3}{|c|}{$\begin{array}{l}\text { ENGLISH } \\
\text { BOOKSHOP }\end{array}$} \\
\hline 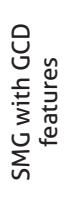 & $\sum_{n}^{U}$ & 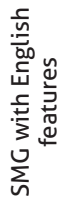 & $\sum_{n}^{U}$ & 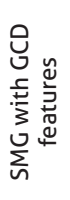 & 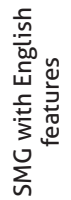 & 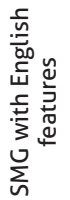 & $\sum_{n}^{U}$ & 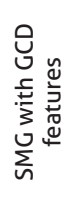 & 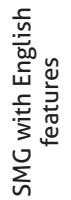 & 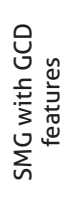 & $\sum_{n}^{U}$ \\
\hline
\end{tabular}


Before distribution, the questionnaire was piloted for clarity of the questions used in the questionnaire and authenticity of language of the advertisements.

\section{The results}

The data collected from the questionnaires were analysed and the findings are presented in four different subsections with the use of tables and figures. Each of the subsection corresponds to each of the four questions included in the questionnaire. It must be noted that the higher the score, the lower the preference, since participants indicated the order of the most preferred advertisement (numbered as 1 ) to the least preferred one (numbered as 3 ).

\subsection{Evaluation of Advertising Texts}

The first question of the questionnaire asked participants to express their preference of the advertising texts $(\mathrm{a}, \mathrm{b}, \mathrm{c})$ in each category $(\mathrm{I}, \mathrm{II}, \mathrm{III})$ comparatively, and rank them $(1,2,3$ from high to low) based on criteria such as aesthetics, vocabulary and target audience. The results are presented in Table 3, in the order given to the participants-random ordering prevents mechanical answering.

Table 3.

Mean evaluation of advertising texts (Question 1)

\begin{tabular}{|c|c|c|c|c|c|c|c|c|c|}
\hline & \multicolumn{3}{|c|}{ STEAKHOUSE } & \multicolumn{3}{|c|}{ ZIVANA } & \multicolumn{3}{|c|}{ CLOTHING } \\
\hline & SMG & ENG & GCD & ENG & SMG & GCD & GCD & SMG & ENG \\
\hline \multicolumn{10}{|l|}{ AESTHETICS } \\
\hline Pleasant & 1,68 & 1,95 & 2,37 & 2,39 & 1,71 & 1,89 & 2,08 & 1,82 & 2,11 \\
\hline Modern & 1,76 & 1,63 & 2,61 & 1,39 & 1,95 & 2,66 & 2,50 & 1,76 & 1,68 \\
\hline Attractive & 1,47 & 1,89 & 2,66 & 2,29 & 1,55 & 2,16 & 2,39 & 1,76 & 1,84 \\
\hline \multicolumn{10}{|l|}{ VOCABULARY } \\
\hline Suitable & 1,32 & 1,92 & 2,76 & 2,42 & 1,32 & 2,26 & 2,37 & 1,58 & 2,05 \\
\hline Functional & 1,29 & 1,89 & 2,82 & 2,24 & 1,53 & 2,24 & 2,42 & 1,58 & 2,00 \\
\hline Familiar & 1,84 & 2,08 & 2,05 & 2,53 & 1,97 & 1,68 & 2,03 & 1,79 & 2,18 \\
\hline \multicolumn{10}{|l|}{ TARGET AUDIENCE } \\
\hline High economic status & 1,58 & 1,58 & 2,84 & 1,82 & 1,61 & 2,58 & 2,45 & 1,68 & 1,87 \\
\hline High educational status & 1,42 & 1,76 & 2,82 & 1,79 & 1,68 & 2,53 & 2,47 & 1,63 & 1,89 \\
\hline
\end{tabular}


The mean values of each code for each product are presented in Figure 1.

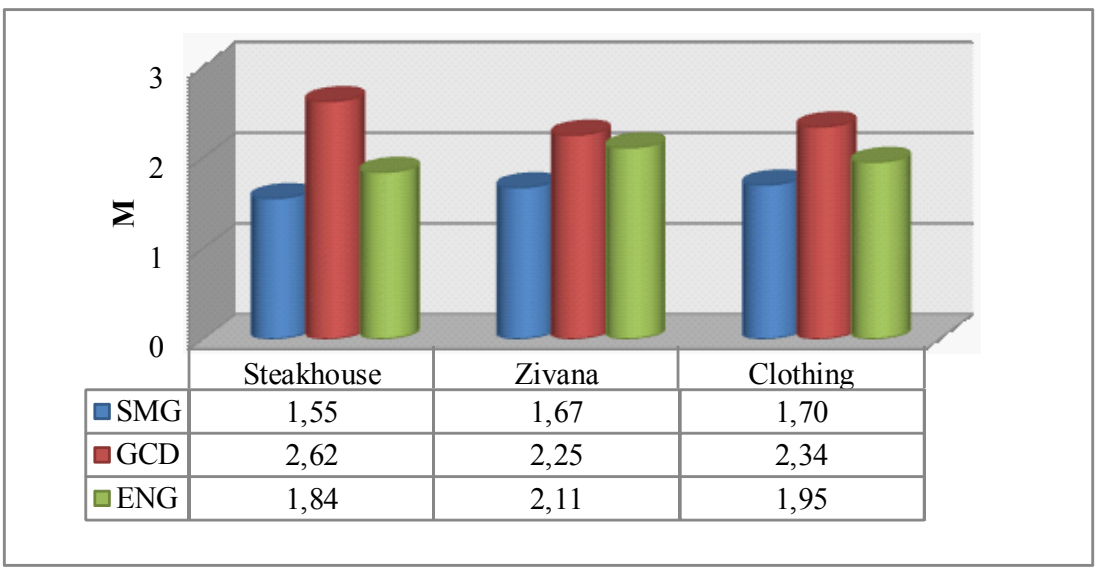

Figure 1. Mean evaluation of GCD, SMG and English (Question 1)

A general observation is that for all three products, SMG is the most preferred code, whereas GCD is the one with the least preference. However, differences are detected in the deviation between the codes' values from one product to the other. SMG and English are mostly preferred in steakhouse advertising, whereas GCD is mostly preferred for zivana (Figure 1). Moreover, although results of SMG seem to be homogeneous from one product to the other, interesting points are raised from the results of GCD and English. Although GCD is generally the least preferred code, it is found to be the most pleasant and familiar in the advertisement of zivana. Also, English is reported to be the least familiar code, but, the most modern one in advertising zivana and clothing, signaling a high economic and educational status. Last, for these two advertisements English is considered as the least attractive, suitable and functional, too.

\subsection{Evaluation of Advertised Products}

The same analysis was followed for Question 2, where the participants show their preference of the advertised products of the same advertisements of each category and rank them in the same way, but, based on criteria of quality, price and target audience. The results are recorded in Table 4. 
Table 4.

Mean evaluation of advertised products (Question 2).

\begin{tabular}{|c|c|c|c|c|c|c|c|c|c|}
\hline & \multicolumn{3}{|c|}{ STEAKHOUSE } & \multicolumn{3}{|c|}{ ZIVANA } & \multicolumn{3}{|c|}{ CLOTHING } \\
\hline & SMG & ENG & GCD & ENG & SMG & GCD & GCD & SMG & ENG \\
\hline \multicolumn{10}{|l|}{ QUALITY } \\
\hline High & 1,21 & 1,87 & 2,92 & 2,24 & 1,53 & 2,24 & 2,63 & 1,50 & 1,87 \\
\hline Reliable & 1,21 & 2,03 & 2,76 & 2,21 & 1,63 & 2,16 & 2,47 & 1,50 & 2,03 \\
\hline \multicolumn{10}{|l|}{ PRICE } \\
\hline Expensive product & 1,66 & 1,58 & 2,76 & 1,61 & 1,74 & 2,66 & 2,61 & 1,79 & 1,61 \\
\hline \multicolumn{10}{|l|}{ TARGET AUDIENCE } \\
\hline High economic status & 1,55 & 1,68 & 2,76 & 1,76 & 1,63 & 2,61 & 2,55 & 1,95 & 1,68 \\
\hline High educational status & 1,45 & 1,74 & 2,82 & 1,89 & 1,66 & 2,45 & 2,58 & 1,66 & 1,76 \\
\hline
\end{tabular}

The mean values of each code for each product are given in Figure 2.

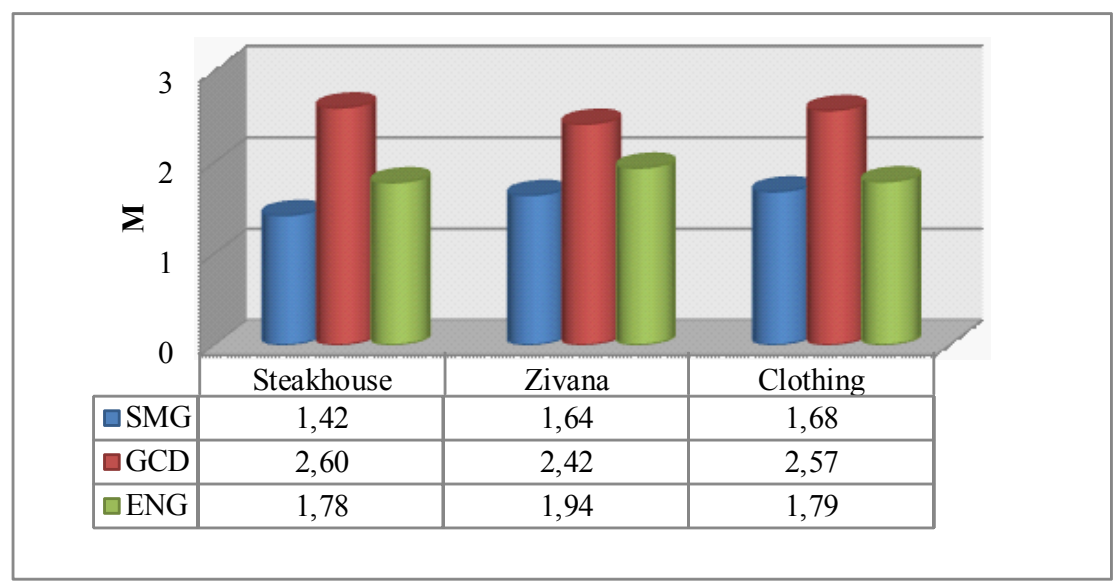

Figure 2. Mean evaluation of GCD, SMG and English (Question 2)

What is mainly observed is that again SMG occupies the first place in people's preference, English is the one that follows and GCD comes last. Nevertheless, it is worth pointing out that English corresponds to the most expensive product in all three categories and adds higher economic status to clothing advertisement. On the contrary, this code is associated with least reliability and equally low quality to GCD in advertising zivana, although its quality is quite unreliable for the other products too. 


\subsection{The influence of the Medium}

Further on, Question 3 instructed participants to categorise the advertisements according to which kind of media is most suitable for each of them to appear in. The first category included oral media (eg. radio or TV) and the second category concerned written media (eg. magazine, newspaper or leaflet). Participants could write the number of the advertisements in both categories, if they regarded them suitable for both kinds (see Figures 3 and 4).

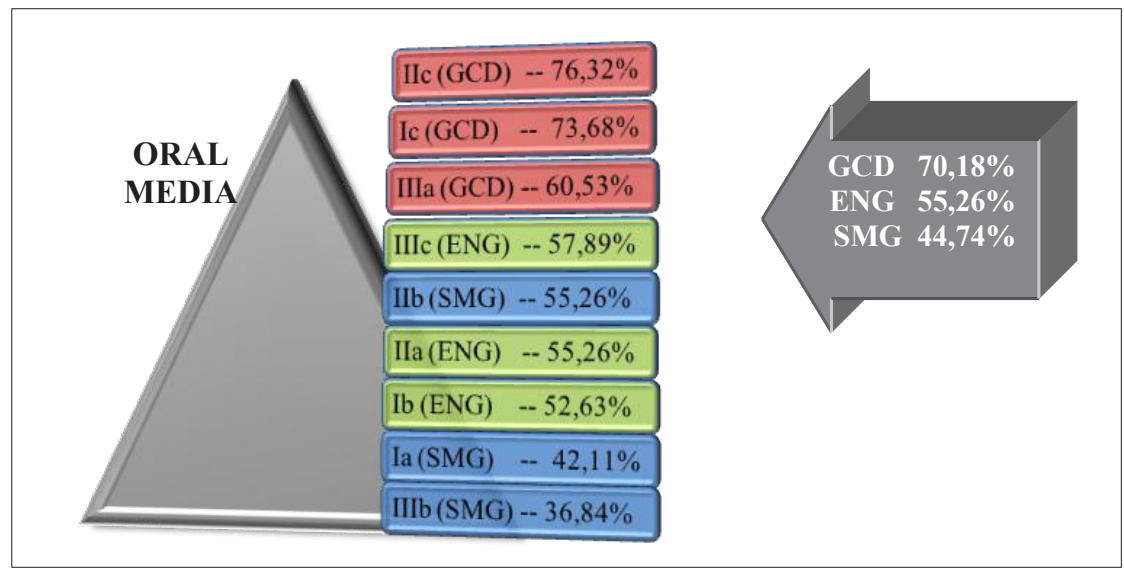

Figure 3. Advertisements/Codes suitable for oral media (Question 3)

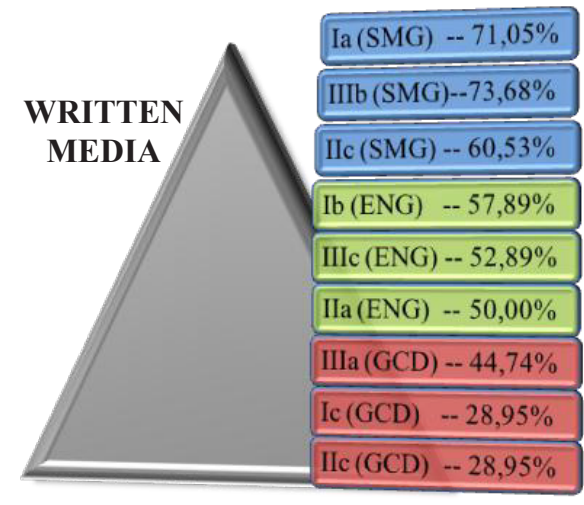

SMG $68,42 \%$

ENG $53,51 \%$

GCD $34,21 \%$

Figure 4. Advertisements/Codes suitable for written media (Question 3) 
The initial conclusion drawn from the figures is that GCD is perceived to be more suitable for oral media while SMG is the least suitable variety for such kind of mass communication. On the other hand, the opposite happens with written media. SMG occupies the first position whereas GCD comes at the bottom of the figure. However, SMG in oral media is accepted by more people than GCD in written media. At last, English comes in the middle position of both figures since half of the participants prefer it in oral presentation and half of them in writing.

\subsection{Suitability of the Code Used}

Finally, the participants were asked to rank (1, 2, 3 from high to low) three advertising texts of four products (Cypriot tavern, champagne, formal clothes and English bookshop), according to which they believe to be the most suitable for each product. The results are presented in Figure 5.

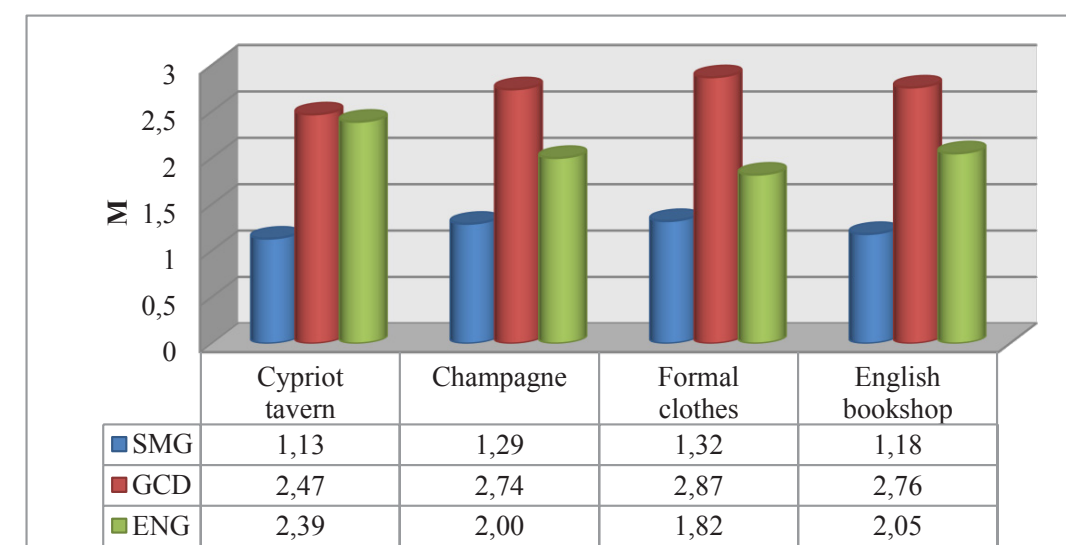

Figure 5. Mean value of GCD, SMG and English (Question 4)

The results show that GCD is regarded as the least suitable code for all products with the highest suitability being observed in the advertisement of Cypriot tavern and the least one in that of formal clothing. Once again, SMG is the code mostly preferred, especially for promoting the Cypriot tavern and then the English bookshop. Similarly, English still occupies the middle place with the least suitability being found in the advertisement of the Cypriot tavern. The English bookshop, champagne and formal clothing follow from less suitable to more suitable. 


\section{Discussion and Conclusions}

$\mathrm{Bi}$-/multilingual and bi-/multidialectal settings have always been a challenge to linguists due to their palpable linguistic wealth that can bring about remarkable conclusions. Such settings, in combination with equally intriguing domains of language use, fascinate experts in language studies. This has provided the stimulation for the present study which focuses on advertising in the Greek-Cypriot community. Based on limited available literature, one can hypothesize that Greek-Cypriots have recently begun to hold a more favourable attitude towards dialect use in advertisements, especially of products reflecting local tradition. Similarly, English should be preferred for products of foreign origin or luxury. Hence, the following questions can be addressed:

Do Greek-Cypriots have positive attitudes towards the appearance of GCD, SMG and English in advertising?

From the results obtained from Questions 1, 2 and 4, it can be concluded that Greek-Cypriots have more positive attitudes towards SMG. English is the second preferred code in advertising, whereas the local dialect comes last (Figures 1, 2 and 3). Deviations from this pattern were found in some products of Questions 1 and 2, for some traits. However, none of them affected the ordering of the codes. People's preference of SMG supports earlier studies that showed greater preference towards the standard variety rather than the dialect (Karyolemou 1994; Papapavlou 1998, 2007; Papapavlou \& Sophocleous 2009). This is rather a universal phenomenon which shows that in many linguistic settings around the world people have more favourable views of the standard variety (Kalmar et al. 1987; Bettoni \& Gibbons 1988; Luhman 1990; Adegbija 1994; Beckford Wassink 1999; de V. Cluver 2000; Broermann 2007).

The finding showing that Greek-Cypriots prefer a foreign code rather than their mother tongue raises several concerns. A possible explanation is that the dialect does not have a writing system and it is used only in oral communication. The high position of English in professional domains has also been observed by McEntee-Atalianis and Pouloukas (2001). This study additionally found that English does not constitute a threat for the two native codes. If the written version of the advertisements did not play a role in the participants' judgment, people's preference for English may have grown from 2001 until today. Such a situation may be due to such factors as globalization and technological development where access is achieved through the lingua franca - like in the case of Africa (Adegbija 1994). 
Does the stereotypical nature of a product (eg. traditional or foreign culture-specific value) affect Greek-Cypriots' attitudes?

In studying Greek-Cypriots' preference of the language of advertising, it is worth stating that the stereotype, or nature, or value reflected in the advertised product does not seem to change people's views (Questions 1, 2 and 4). Nevertheless, minor stereotype influence is observed, in cases people judged with the use of traits (Questions 1 and 2), even though it does not affect the final result.

In the case of the foreign and luxury product (steakhouse), people consider English intervention as the most modern, but, the least familiar text, advertising the most expensive product. Moreover, in the case of a product which is of Cypriot origin and tradition (zivana), GCD is thought to be the most familiar kind of language. Similarly, in Question 4, GCD is more acceptable for the Cypriot tavern than any other product. On the other hand, English carries the label of the most modern in advertising zivana, but, the least pleasant, attractive, suitable and familiar code, adding unreliability and cost to the product. This can serve as a counterbalance to the previous concern since it can be a sign that English remains a foreign element of no trust within the community.

Does the medium (oral or written) used to present the advertisements influence Greek-Cypriots' attitudes?

From the answers to Question 3 of the questionnaire, we detect influence of the medium of presentation on people's view of the advertising language. The written mode is more preferable for SMG and, then, English. GCD is the least favoured code for written media, but, it is the first appearing in oral presentation. What has most likely driven people to such a categorization is the fact that GCD is the only investigated code that has not been codified yet; therefore, it remains unacceptable or 'weird ' for it to appear in written form. An alternative explanation is that writing is a more formal kind of communication - where people are expected to use SMG - whereas orality is more associated with casualty and everyday life - where people use GCD. Additionally, English can be found in written advertisements, but, not as often as a more native and comprehensible code (SMG).

People's support for English more than SMG in oral media is rather interesting. This can stand as an indication of an already existing situation; the inadequate usage of SMG. Although SMG is the official language of the state, in trying to speak SMG, Greek-Cypriots end up with a mixture called Cypriot Standard Greek (Arvaniti 2006).Conversely, English language's dominance over SMG in oral communication shows that people are more used to or in favour of listening and speaking English rather than SMG. Previous research has recognized the 
important role of English in Cyprus, but, it has been claimed that it is related to certain social contexts (Goutsos 2005) and people "share a common understanding of their national linguistic identity, cultural heritage and language preferences" that do not let foreign elements to weaken it (McEntee-Atalianis $\&$ Pouloukas 2001:35). However, anglicisms are constantly increasing, changing people's linguistic preferences.

In conclusion, as Kelly-Holmes (2005) argues, while advertisers appear to support that the nature of the product requires a certain linguistic code that is best for promoting it, recipients themselves do not seem to share this view . The present study demonstrated that while people are not absolutely negative towards the use of GCD in advertising local products, they still prefer SMG as in other domains of their life (Karyolemou 1994; Papapavlou 1998, 2007; Papapavlou \& Sophocleous 2009 etc). This view is more firm in the case of written media, where SMG is the most acceptable code, by contrast to GCD which is preferred for oral presentation. Additional studies are needed to further explore the intricacies of this phenomenon. 


\section{References}

Adegbija, E. 1994. Language Attitudes in Sub-Saharan Africa: A Sociolinguistic Overview. Clevedon: Multilingual Matters.

Arvaniti, A. 2006. Linguistic practices in Cyprus and the emergence of Cypriot Standard Greek. In San Diego Linguistic Papers, 2: 1-24.

Atkinson, D. and H. Kelly-Holmes. 2006. Linguistic normalisation and the market: Advertisingand linguistic choice in El Periódico de Catalunya. In Language Problems and Language Planning, 30 (3). John Benjamins, 239-260.

Baker, C. 1992. Attitudes and Language. Clevedon: Multilingual Matters Ltd.

Beckford Wassink, A. 1999. Historic low prestige and seeds of change: Attitudes toward Jamaican Creole.In Language in Society, 28. Cambridge University Press, 57-92.

Bettoni, C. and J. Gibbons. 1988. Linguistic purism and language shift; a guisevoice study of the Italian community in Sydney. In International Journal of the Sociology of Language, 72. Amsterdam: Mouton de Gruyter, 15-35.

Broermann, M. 2007. Language attitudes among minority youth in Finland and Germany. In International Journal of the Sociology of Language, 187/188: 129160.

Bruthiaux, P. 1996. The Discourse of Classified Advertising. Oxford: Oxford University Press.

Chen, W.-Y.C. 2006. The mixing of English in magazine advertisements in Taiwan. In World Englishes, 25 (3/4). Oxford: Blackwell, 467-478. 
Choi, J. 2003. Language attitudes and the future of bilingualism: the case of Paraguay. In International Journal of Bilingual Education and Bilingualism, 6 (2): 81-94.

Cook, G. 2006. The Discourse of Advertising (Second Edition). London, New York: Routledge.

de V. Cluver, A. 2000. Changing language attitudes: The stigmatisation of Khoekhoegowap in Namibia. In Language Problems and Language Planning, 24 (1). Amsterdam: John Benjamins Publishing Company, 77-100.

Dyer, G. 1982. Advertising as Communication. London, New York: Methuen \& Co. Ltd.

Garrett, P., N. Coupland and A. Williams. 2003. Investigating Language Attitudes. Cardiff: University of Wales Press.

Goutsos, D. 2005. A discourse-analytic approach to the use o English in Cypriot Greek conversations. In A. Papapavlou (ed.), Contemporary Sociolinguistic Issues in Cyprus. Thessaloniki: University Studio Press, 181-212.

Harris, R., R. Sturm, M. Klassen and J. Bechtold. 2002. Language in advertising: a psycholinguistic approach. In Original Research and Theoretical Contributions. EBSCO Publishing, 1-26.

Hornikx, J., F. van Meurs and A. Boer. 2010. English or a local language in advertising? The appreciation of easy and difficult English slogans in the Netherlands. In Journal of Business Communication, 47 (2). Nijmegen: Association for Business Communication, 169-188.

Kalmar, I., Z. Yong and X. Hong. 1987. Language attitudes in Guangzhou, China. In Language in Society, 16. Cambridge University Press, 499-508.

Karyolemou, M. 1994. Linguistic attitudes and metalinguistic discourse: An investigation in the Cypriot press. In I. Philippaki-Warburton, K. Nicolaidisand M. Sifianou (eds.), Themes in Greek Linguistics. Amsterdam: John Benjamins, 253-259.

Karyolemou, M. 2001. From linguistic liberalism to legal regulation: The Greek language in Cyprus. In Language Problems and Language Planning, 25 (1): 25-51.

Kelly-Holmes, H. 2005. Advertising as Multilingual Communication. New York: Palgrave Macmillan. 
Krishnasamy, K. 2007. English in Tamil: The language of advertising. In English Today, 23 (3/4). Cambridge University Press, 40-49.

Lambert, W., R. Hodgson, R. Gardner and S. Fillenbaum. 1960. Evaluational reactions to spoken language. In Journal of Abnormal and Social Psychology, 60: 44-51.

Luhman, R. 1990. Appalachian English stereotypes: Language attitudes in Kentucky. In Language in Society, 19. Cambridge University Press, 331-348.

Martin, E. 2006. Marketing Identities through Language: English and Global Imagery in French Advertising. New York: Palgrave Macmillan.

McEntee-Atalianis, L. and S. Pouloukas. 2001. Issues of identity and power in a Greek-Cypriot community. In Journal of Multilingual and Multicultural Development, 22 (1): 19-38.

Mutonya, M. 2008. Swahili advertising in Nairobi: Innovation and language shift. In Journal of African Cultural Studies, 20 (1). Routledge, 3-14.

Papapavlou, A. 1994. Language Contact and Lexical Borrowing in the Greek Cypriot Dialect: Sociolinguistic and Cultural Implications. Athens: N.C. Grivas Publications.

Papapavlou, A. 1997. The influence of English and its dominance in Cyprus: Reality or unfounded fears? In Journal of Mediterranean Studies, 7: 1-32.

Papapavlou, A. 1998. Attitudes towards the Greek Cypriot dialect: Sociocultural implications. In International Journal of the Sociology of Language, 134: 15-28.

Papapavlou, A. 2007. Language policy and planning: The role of language attitudes in decision making. In A. Papapavlou and P. Pavlou (eds.), Sociolinguistic and Pedagogical Dimensions of Dialects in Education. Newcastle: Cambridge Scholars Publishing, 194-215.

Papapavlou, A. and T. Kouridou. 2007. Bidialectism and metalinguistic awareness. In A. Papapavlou and P. Pavlou (eds.), Sociolinguistic and Pedagogical Dimensions of Dialects in Education. Newcastle: Cambridge Scholars Publishing, 216-235.

Papapavlou, A. and P. Pavlou. 1998. A review of the sociolinguistic aspects of the Greek Cypriot Dialect. In Journal of Multilingual and Multicultural Development, 19 (3): 212-220. 
Papapavlou, A. and P. Pavlou. 2004. Issues of dialect use in education from the Greek Cypriot perspective. In International Journal of Applied Linguistics, 14 (2). Oxford: Blackwell Publishing, 243-259.

Papapavlou, A. and P. Pavlou. 2007. The interplay of bidialectalism, literacy and educational policy. In A. Papapavlou and P. Pavlou (eds.), Sociolinguistic and Pedagogical Dimensions of Dialects in Education. Newcastle: Cambridge Scholars Publishing, 101-121.

Papapavlou, A. and A. Sophocleous. 2009. Relational social deixis and the linguistic construction of identity. In International Journal of Multilingualism:1-16.

Pavlou, P. 1992. The use of the Cypriot-Greek Dialect in the commercials of the Cyprus Broadcasting Corporation. Paper presented at the 37th Conference on the International Linguistics Association, Washington DC.

Pavlou, P. 2001. The use of dialectal and foreign language elements in radio commercials and their function in the construction of contemporary Cypriot identity. Paper given at the international conference Mèditerrannée: Ruptures et Continuités, Nicosia, Cyprus.

Pavlou, P. 2004. Greek dialect use in the mass media in Cyprus. In International Journal of the Sociology of Language, 168. Walter de Gruyter, 101-118.

Piller, I. 2001. Identity constructions in multilingual advertising. In Language in Society 30.Cambridge: Cambridge University Press, 153-185.

Piller, I. 2003. Advertising as a site of language contact. In Annual Review of Applied Linguistics 23. Cambridge: Cambridge University Press, 170-183.

Planken, B., F. van Meurs and A. Radlinska. 2010. The effects of the use of English in Polish product advertisements: Implications for English for business purposes. In English for Specific Purposes, 29. Nijmegen: Elsevier, 225-242.

Rash, F. 1996. Attitudes to the use of English in Swiss German advertising language. In The Web Journal of Modern Language Linguistics, 1. University of Newcastle upon Tyne: School of Modern Languages.

Sophocleous, A. 2004. The History of Advertising in Cyprus. Nicosia: Laiki Group Cultural Centre. 
Tanaka, K. 1994. Advertising Language: A Pragmatic Approach to Advertisements in Britain and Japan. London, New York: Routledge.

Themistocleous, C. 2007. Written Cypriot Greek in online chat: Usage and attitudes. In Proceedings of the 17th International Postgraduate Linguistics Conference. Manchester: Department of Linguistics and English language, 473488.

Trudgill, P. 1992. Introducing Language and Society. London: Penguin English.

Tsiplakou, S. 2003. Attitudes towards language and language change: A two-way relationship? [in Greek]. In Proceedings of the 6th International Conference on Greek Linguistics.

Tsiplakou, S., A. Papapavlou, P. Pavlou and M. Katsoyannou. 2005. Levelling, koineization and their implications for bidialectism. In Language VariationEuropean Perspectives: Selected Papers from the 3rd International Conference on Language Variation in Europe. John Benjamins, 265-276.

Varella, S. 2006. Language Contact and the Lexicon in the History of Cypriot Greek. Bern: Peter Lang.

Vestergaard, T. and K. Schrøder. 1985. The Language of Advertising. Oxford: Blackwell.

Wyer, R. 2002. Language and advertising effectiveness: mediating influences of comprehension and cognitive elaboration. In Psychology and Marketing 19 (7-8). Wiley InterScience, 693-712.

Yiakoumetti, A., M. Evans and E. Esch. 2006. Language awareness in a bidialectalsetting: The oral performance and language attitudes of urban and rural students in Cyprus. In Language Awareness, 14 (4). London: Routledge, 254260. 


\section{Appendix A}

\section{Advertisements}

\section{CATEGORY I}

a) JACK'S steakhouse

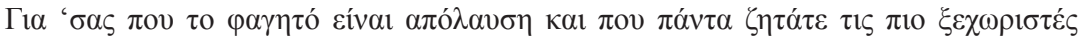

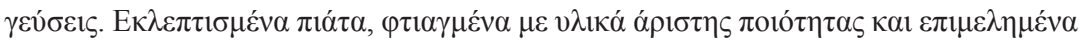

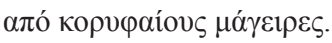

b) STEVEN'S steakhouse

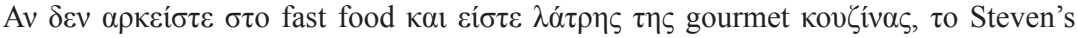

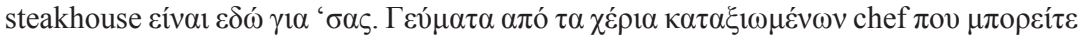
$v \alpha \alpha \pi \mathrm{\alpha} \alpha v_{\sigma \varepsilon \tau \varepsilon}^{\sigma \varepsilon} \mu 1 \alpha$ chic $\alpha \tau \mu o ́ \sigma \varphi \alpha \imath \rho \alpha$.

c) KEN'S steakhouse

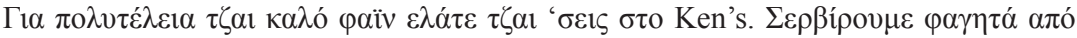

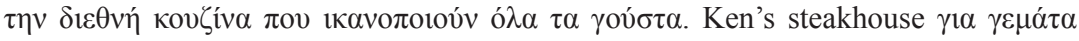

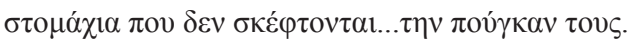

\section{CATEGORY II}

a) Zıßóv $\alpha$ XO $\Lambda$ ETPIA

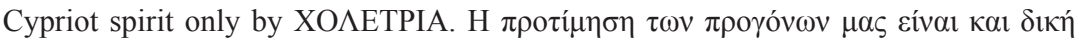

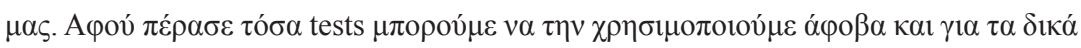
$\mu \alpha \varsigma$ parties.

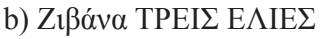

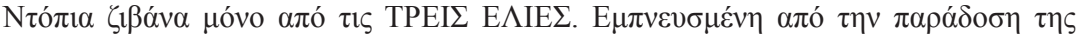

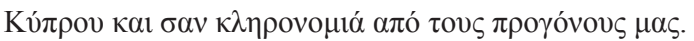

c) Zıßóva ПА

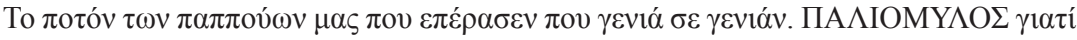

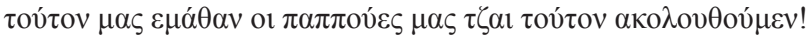

\section{CATEGORY III}

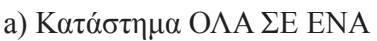

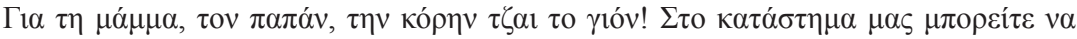

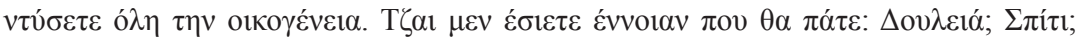

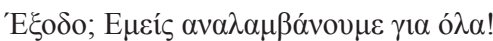




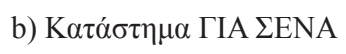

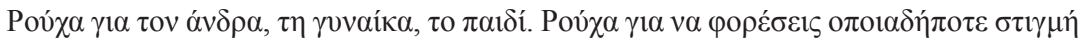

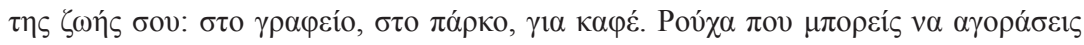

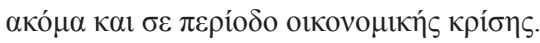

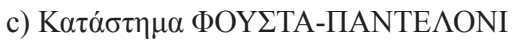

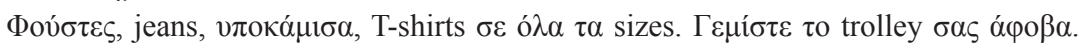

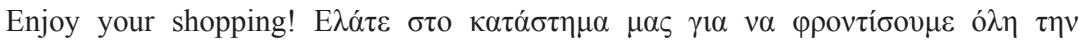

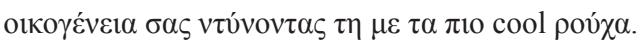




\section{Appendix B}

\section{Questions}

\section{MEPO $\Sigma$ A}

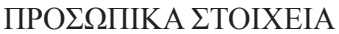

Фúlo:

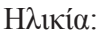

Тó

\section{MEPO $\Sigma$ B}

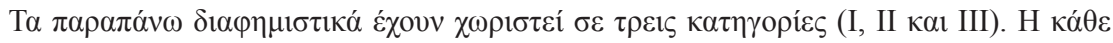

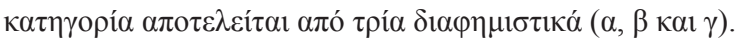

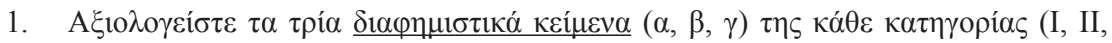

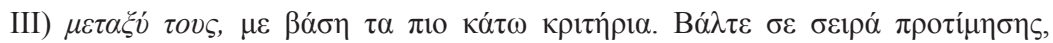

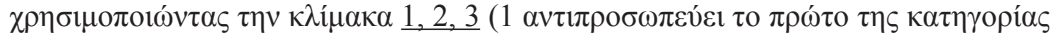

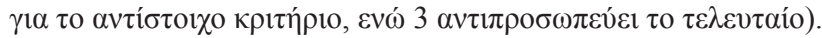

\begin{tabular}{|c|c|c|c|c|c|c|c|c|c|}
\hline & \multicolumn{3}{|c|}{ КАТНГОРІА I } & \multicolumn{3}{|c|}{ КАТНГОРІА II } & \multicolumn{3}{|c|}{ КАТНГОРІА III } \\
\hline & $\alpha$ & $\beta$ & $\gamma$ & $\alpha$ & $\beta$ & $\gamma$ & $\alpha$ & $\boldsymbol{\beta}$ & $\gamma$ \\
\hline \multicolumn{10}{|l|}{$\mathrm{AI} \Sigma \Theta H T I K H$} \\
\hline \multicolumn{10}{|l|}{ 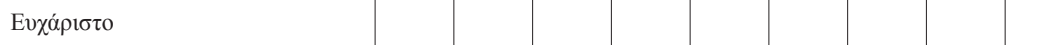 } \\
\hline \multicolumn{10}{|l|}{ 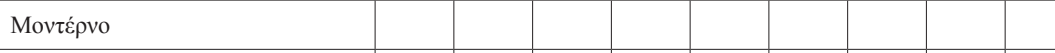 } \\
\hline \multicolumn{10}{|l|}{ 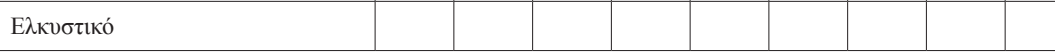 } \\
\hline \multicolumn{10}{|l|}{ 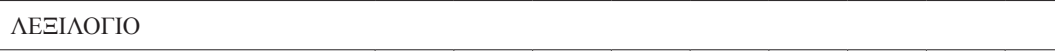 } \\
\hline \multicolumn{10}{|l|}{$\mathrm{K} \alpha \tau \alpha \dot{\lambda} \lambda \lambda \eta \lambda \mathrm{o}$} \\
\hline \multicolumn{10}{|l|}{ 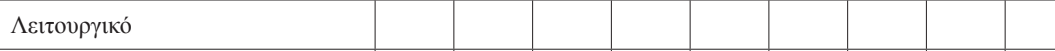 } \\
\hline \multicolumn{10}{|l|}{ Оıквío } \\
\hline \multicolumn{10}{|c|}{ KOINO TO OПOIO ऽTOXЕYЕI } \\
\hline \multicolumn{10}{|l|}{ 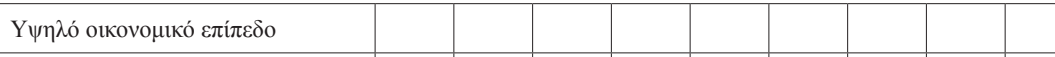 } \\
\hline 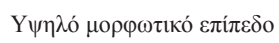 & & & & & & & & & \\
\hline
\end{tabular}

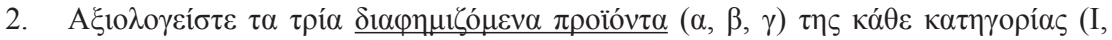

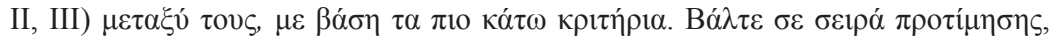

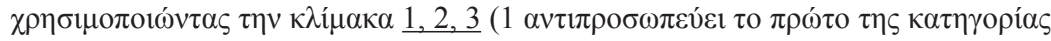

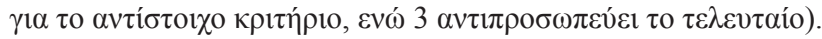




\begin{tabular}{|c|c|c|c|c|c|c|c|c|c|}
\hline & \multicolumn{3}{|c|}{ КАТНГОРІА I } & \multicolumn{3}{|c|}{ КАТНГОРІА II } & \multicolumn{3}{|c|}{ КАТНГОРІА III } \\
\hline & $\alpha$ & $\beta$ & $\gamma$ & $\alpha$ & $\beta$ & $\gamma$ & $\alpha$ & $\beta$ & $\gamma$ \\
\hline \multicolumn{10}{|l|}{ ПОІОТНТА } \\
\hline \multicolumn{10}{|l|}{ Y $\psi \eta \lambda \eta ́$} \\
\hline \multicolumn{10}{|l|}{ 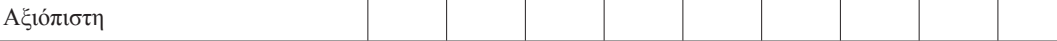 } \\
\hline \multicolumn{10}{|l|}{ TIMH } \\
\hline \multicolumn{10}{|l|}{ 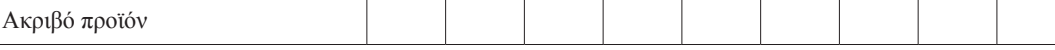 } \\
\hline \multicolumn{10}{|c|}{ KOINO TO OПOIO ऽTOXEYEI } \\
\hline \multicolumn{10}{|l|}{ 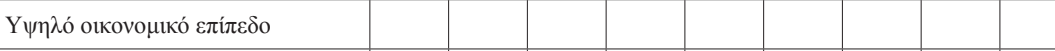 } \\
\hline 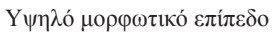 & & & & & & & & & \\
\hline
\end{tabular}

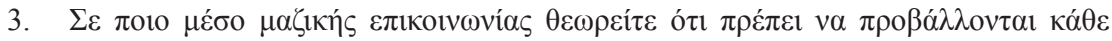

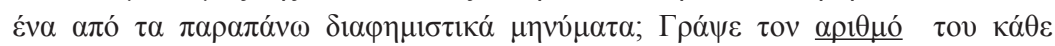

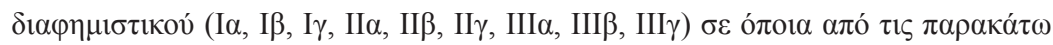

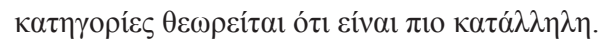

\begin{tabular}{|c|c|}
\hline 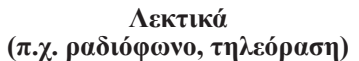 & 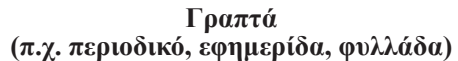 \\
\hline & \\
\hline & \\
\hline & \\
\hline & \\
\hline & \\
\hline & \\
\hline
\end{tabular}

\section{$\operatorname{MEPO} \Gamma$}

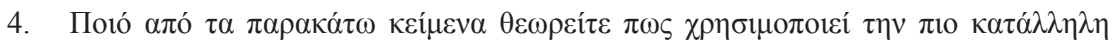

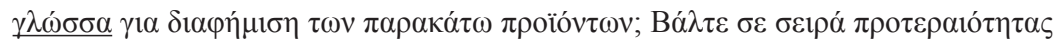

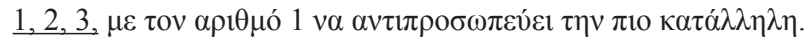

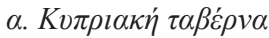

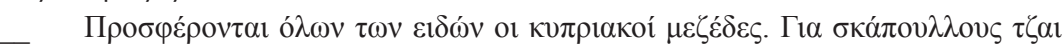

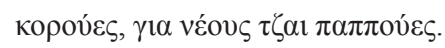

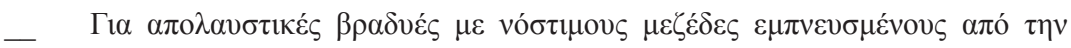

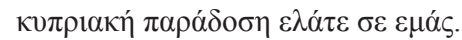

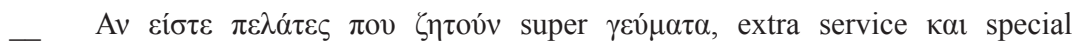

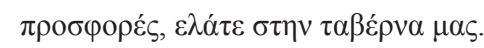




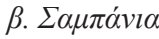

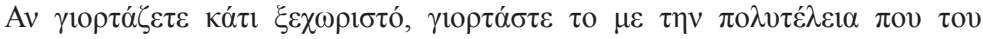
$\alpha \rho \mu o ́ \zeta \varepsilon 1$.

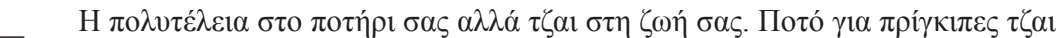
$\beta \alpha \sigma i \lambda \alpha_{1} \varepsilon \varsigma$.

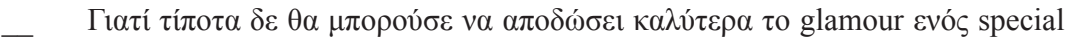

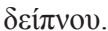

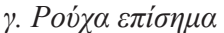

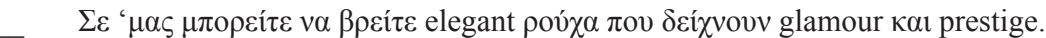

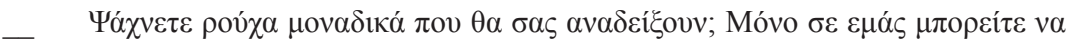
$\tau \alpha \beta \rho \varepsilon i ́ \tau \varepsilon$

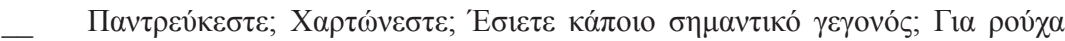

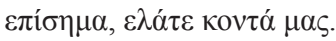

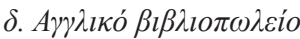

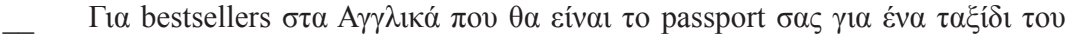
$\mu v \alpha \lambda \circ v$ $\sigma \tau$ o Buckingham Palace.

— T T

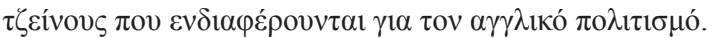

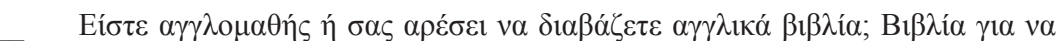

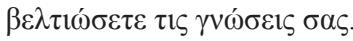

